\title{
EchoGéo
}

\section{Le Forum Urbain Mondial : un lieu et un moment pour penser la ville?}

\author{
Introduction
}

\section{Alexis Sierra et Karine Peyronnie}

\section{OpenEdition}

Journals

\section{Édition électronique}

URL : https://journals.openedition.org/echogeo/11901

DOI : 10.4000/echogeo.11901

ISSN : 1963-1197

\section{Éditeur}

Pôle de recherche pour l'organisation et la diffusion de l'information géographique (CNRS UMR 8586)

\section{Référence électronique}

Alexis Sierra et Karine Peyronnie, « Le Forum Urbain Mondial : un lieu et un moment pour penser la ville? », EchoGéo [En ligne], 12 | 2010, mis en ligne le 31 mai 2010, consulté le 31 juillet 2021. URL: http://journals.openedition.org/echogeo/11901; DOI : https://doi.org/10.4000/echogeo.11901

Ce document a été généré automatiquement le 31 juillet 2021.

EchoGéo est mis à disposition selon les termes de la licence Creative Commons Attribution - Pas d'Utilisation Commerciale - Pas de Modification 4.0 International (CC BY-NC-ND) 


\title{
Le Forum Urbain Mondial : un lieu et un moment pour penser la ville?
}

\author{
Introduction
}

\author{
Alexis Sierra et Karine Peyronnie
}

1 Ce dossier «Sur le métier » a pour point de départ le V ème Forum Urbain Mondial qui s'est déroulé à Rio de Janeiro (Brésil) du 22 au 26 mars 2010. Les précédents forums ont eu lieu à Nairobi (2002), à Barcelone (2004), à Vancouver (2006) et à Nankin (2008).

2 Organisé par ONU-Habitat depuis 2002 pour répondre aux enjeux de l'urbanisation rapide du monde, le Forum Urbain Mondial est un de ces moments qui participent à la mondialité pour reprendre l'expression de Denis Retaillé : une rencontre d'acteurs divers qui appréhendent une dynamique mondiale (l'urbanisation) dans une vision interdépendante du monde et qui élaborent à l'échelle internationale des notions, des problématiques et des instruments universalisables c'est-à-dire déclinables en tout lieu de la planète. Avec 13700 participants (élus, administrateurs, scientifiques, experts, associatifs) provenant de 150 pays du Sud et du Nord, le Forum Urbain Mondial de Rio est une étape dans la constitution d'une communauté épistémique mondiale (GhorraGobin) dont l'objet est l'urbain. Contrairement à la majorité des thèmes portés internationalement (la pauvreté, l'eau, ...), l'urbain renvoie directement à une société locale inscrite territorialement avec pour ambition holiste de croiser les différentes thématiques du développement (lutte contre les inégalités, contre la pauvreté, contre le réchauffement climatique, contre les catastrophes, contre la ségrégation sociale et de genre, etc...) et de construire un " projet de ville », l'expression étant récurrente.

Du fait du contexte brésilien et des orientations de ONU Habitat, la thématique urbaine a été déclinée à travers la question du "droit à la ville» afin de «combler le fossé urbain ». La question de la participation citoyenne dans la construction urbaine et dans " l'accès à la ville » était récurrente. Sans être jamais précisément défini, l'accès à la ville sous entendait l'accès aux services essentiels, l'accès au foncier et au logement dans les différentes parties de la ville, l'accès à l'espace public ou l'accès aux processus de prise de décision locale ou encore la combinaison de l'ensemble. Dans ce contexte, les politiques publiques néo-libérales $d u$ foncier et du droit à la terre étaient 
sévèrement critiquées. A l'occasion de ce forum, la campagne urbaine mondiale de " comblement du fossé urbain » (campaign to bridge the urban divide) d'ONU Habitat a été lancée. Celle-ci met l'accent sur l'accès aux services essentiels pour tous. Elle commence par les 100 «meilleures villes » dans ce domaine dont 21 villes pilotes - telle Alicante en Espagne-, lesquelles partageront et échangeront leurs bonnes pratiques de " développement durable».

Ces questions sont éminemment géographiques: elles obligent à un savoir penser l'espace urbain, dans ses dimensions physiques et sociales, à différents niveaux d'analyse, de l'échelle du quartier à la prise en compte des dynamiques générales de métropolisation. Si les géographes, qu'ils soient chercheurs, universitaires ou experts étaient présents au FUM, nous découvrons qu'ils restent relativement en retrait de l'action portée en France sur l'urbain alors même que leurs compétences sont reconnues. Un bref historique de la géographie urbaine française donnera un éclairage pour situer le parcours de deux passionnés villes : le sénateur Yves Dauge, chef de la délégation française au FUM, et Serge Allou, représentant du Groupe de Recherche et d'Echange Technologique. Le premier montrera que penser la ville de demain passe par la compréhension des centres historiques dont il est un défenseur passionné. Le second, que le « droit à la ville » peut être un levier de la lutte contre les relégations à condition de combiner l'action sur ses diverses composantes.

Les deux se rejoignent sur de nombreux points. Leur action montre la nécessité de penser l'urbain pour penser la transversalité des problèmes sociaux. La ville n'est pas pour eux qu'un cadre de l'action mais aussi un objet sur lequel il faut agir dans sa globalité. Les deux pensent la ville comme espace de citoyenneté et d'élaboration de politiques publiques. Des espaces intrinsèquement porteurs de démocratie même s'il s'agit d'une démocratie à construire. Enfin, les deux montrent que le découpage Nord/ Sud, bien qu'insatisfaisant, reste un paradigme qui conditionne l'action, action qui doit se faire en collaboration étroite avec les acteurs locaux.

\section{AUTEURS}

\section{ALEXIS SIERRA}

Alexis Sierra est maître de conférence, géographe et membre de l'UMR PRODIG alexisierra2001@yahoo.fr

\section{KARINE PEYRONNIE}

Karine Peyronnie est chercheur à l'IRD, géographe et membre de l'UMR PRODIG karine.peyronnie@ird.fr 